\title{
The bispectral index response to tracheal intuba- tion is similar in normotensive and hypertensive patients
}

\author{
[La réponse de l'index bispectral à l'intubation endotrachéale est similaire chez les
} patients normotendus et hypertendus]

Masayasu Nakayama MD, * Hiromichi Ichinose MD, $†$ Shuji Yamamoto MD, $†$ Noriaki Kanaya MD, ${ }^{*}$ Akiyoshi Namiki MD PhD*

Purpose: To compare the hemodynamic and bispectral index (BIS) responses to tracheal intubation in normotensive and hypertensive patients.

Method: Three minutes after induction of anesthesia with thiamylal and fentanyl, tracheal intubation was performed in 24 normotensive and 22 hypertensive patients. Heart rate (HR), mean arterial pressure (MAP), and BIS were measured every minute.

Results: Tracheal intubation increased HR, MAP, and BIS in both normotensive and hypertensive patients. The increase in MAP was significantly greater in hypertensive patients than in normotensive patients, but there were no differences in HR or BIS in the two groups of patients.

Conclusion: Patients with and without hypertension exhibit the same arousal response (as measured by BIS) to tracheal intubation despite the enhanced vasopressor response in hypertensive patients.

Objectif : Comparer les réponses hémodynamiques et de l'index bispectral (BIS) à l'intubation endotrachéale chez des patients normotendus et hypertendus.

Méthode : Trois minutes après l'induction de l'anesthésie avec du thiamylal et du fentanyl, l'intubation endotrachéale a été réalisée chez 24 patients normotendus et 22 hypertendus. La fréquence cardiaque (FC), la tension artérielle moyenne (TAM) et le BIS ont été mesurés à toutes les minutes.

Résultats : L'intubation endotrachéale a fait augmenter la FC, la TAM et le BIS chez les patients des deux groupes. L'accroissement de la TAM a été significativement plus élevé chez les hypertendus, mais il n'y a pas eu de différence intergroupe pour la FC ou le BIS.
Conclusion : Les patients hypertendus ou non réagissent par la même réaction d'éveil (mesurée par le BIS) à l'intubation endotrachéale malgré l'augmentation de la réponse vasopressive chez les hypertendus.

$\longrightarrow$ HE bispectral index (BIS), obtained from bispectral analysis of the electroencephalogram (EEG), reflects the hypnotic component of anesthesia. ${ }^{1-3}$ Previous studies have shown that tracheal intubation is associated with increases in BIS as well as heart rate (HR) and blood pressure. $^{4-6}$ Therefore, intubation is likely to affect both the hypnotic and antinociceptive components of anesthesia. Although the enhanced hemodynamic response to intubation in patients with hypertension is well documented, ${ }^{7,8}$ the degree of the arousal response has not been studied. The objective of the present study was to compare the changes in hemodynamic responses and BIS induced by tracheal intubation in normotensive and hypertensive patients.

\section{Methods}

The study was approved by our local Ethics Committee, and informed consent for participation in the study was obtained from each patient. Twenty-four normotensive patients (Group $\mathrm{N}$ ) and 22 hypertensive patients (Group H) scheduled for elective surgery with general anesthesia were enrolled. All hypertensive patients had a diagnosis of essential hypertension. They were already receiving oral medication consisting of a calcium antag-

From the Department of Anesthesiology, ${ }^{*}$ Sapporo Medical University School of Medicine, Sapporo; and the Division of Anesthesia, $\dagger$ Obihiro Kosei Hospital, Obihiro, Japan.

Address correspondence to: Dr. Masayasu Nakayama, Department of Anesthesiology, Sapporo Medical University School of Medicine,

South 1, West 16, Chuoku, Sapporo 060-8543, Japan. Phone: +011 611-2111; Fax: +011 631-9683; E-mail: miyabi@zc4.so-net.ne.jp Accepted for publication December 11, 2001.

Revision accepted January 18, 2002. 
onist (nifedipine or nicardipine) and received their medication on the day of surgery. None of the patients had an abnormal electrocardiogram (ECG) or neurological disorders on admission.

No premedication was given before surgery. ECG (lead II) and hemoglobin oxygen saturation $\left(\mathrm{SpO}_{2}\right)$ were monitored continuously throughout the procedure. HR and mean arterial pressure (MAP) were measured by an automatic oscillographic method. BIS (version 3.4) was measured continuously on an EEG monitor (Model A1050; Aspect Medical System, Natick, MA, USA) using BisSensor strips (Aspect Medical System). The impedance of each electrode was maintained at less than 2 kilohms.

General anesthesia was induced with $5 \mathrm{mg} \cdot \mathrm{kg}^{-1}$ of thiamylal and $2 \mu \mathrm{g} \cdot \mathrm{kg}^{-1}$ of fentanyl $i v$. After loss of consciousness, $0.1 \mathrm{mg} \cdot \mathrm{kg}^{-1}$ of vecuronium iv was given, and the patient's lungs were ventilated by mask with 6 $\mathrm{L} \cdot \mathrm{min}^{-1}$ of oxygen via a semiclosed circle system. Three minutes after induction, direct laryngoscopy for orotracheal intubation was initiated by one of the authors (M.N.) and was accomplished within $30 \mathrm{sec}$. After intubation, ventilation was controlled with $1 \%$ sevoflurane in oxygen for five minutes.

$\mathrm{HR}, \mathrm{MAP}$, and BIS were recorded before the induction of anesthesia and every minute during the study

TABLE I Demographic data

\begin{tabular}{lll}
\hline & Normotensive & Hypertensive \\
\hline Sex $($ female / male) $(n)$ & $13 / 11$ & $11 / 11$ \\
Age $(\mathrm{yr})$ & $41 \pm 10$ & $45 \pm 11$ \\
Weight $(\mathrm{kg})$ & $67 \pm 12$ & $70 \pm 10$ \\
Height $(\mathrm{cm})$ & $166 \pm 14$ & $165 \pm 8$ \\
Duration of & $22 \pm 7$ & $20 \pm 9$ \\
laryngoscopy $(\mathrm{sec})$ & & \\
\hline
\end{tabular}

Values are means \pm SD. No statistically significant differences between groups. period. All data are expressed as means \pm SD. Statistical analysis was performed using two-way analysis of variance (between the groups) followed by post hoc analyses with Fisher's protected least significant difference test. The chi-squared test was used to compare gender differences between the two groups. A $P$ value $<0.05$ was considered statistically significant.

\section{Results}

Patients' characteristics, baseline hemodynamics and BIS in the two groups were similar (Tables I and II). MAP and BIS decreased significantly after induction of anesthesia, but there was no significant change in HR in either group. The decreases in MAP and BIS with anesthetic induction (preintubation) were similar in the two groups.

In both groups, intubation caused significant increases in HR, MAP and BIS. The increases in MAP after intubation were sustained for three minutes in Group $\mathrm{N}$ and for four minutes in Group $\mathrm{H}$. The greatest increases in hemodynamic variables occurred at one minute after intubation. The significant increases in BIS were seen only at two minutes after intubation in both groups. The increase in MAP after intubation was significantly greater in Group $\mathrm{H}$ than in Group N, but there were no inter-group differences at any time in increases in HR and BIS due to intubation.

Abnormal ECG or $\mathrm{SpO}_{2}$ less than $98 \%$ was not observed throughout the study period. None of the patients complained of awareness during anesthesia.

\section{Discussion}

The present study shows that the hypertensive response to tracheal intubation was greater in patients with hypertension than in normotensive patients, whereas the increases in BIS in these two groups of patients were not different.

Although a reflex response to a noxious stimulus

TABLE II Changes in mean arterial pressure (MAP), heart rate (HR), and bispectral index (BIS)

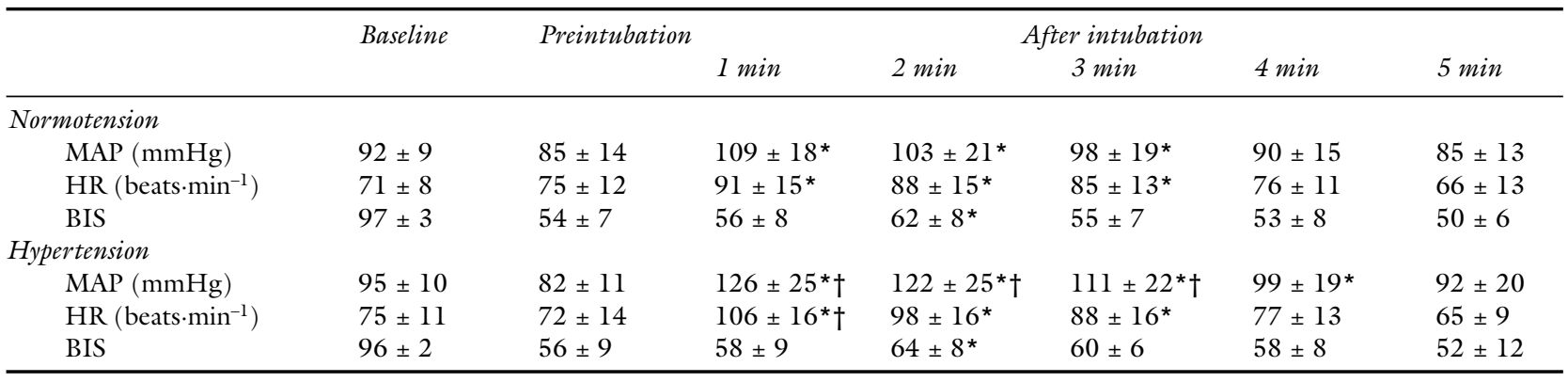

Values are means $\pm \mathrm{SD} ;{ }^{*} P<0.05$ vs preintubation; $\dagger P<0.05$ vs normotension; Preintubation $=$ after induction of anesthesia - prior to intubation. 
due to tracheal intubation is mediated at the subcortical level, ${ }^{4}$ peripheral stimuli reach the brain through the ascending reticular activating systems of the brain stem and may affect the state of consciousness. ${ }^{9} \mathrm{Mi}$ et al. ${ }^{4}$ reported that BIS was significantly increased by laryngoscopy and intubation during infusion of propofol with or without fentanyl pretreatment. Guignard et al. ${ }^{5}$ demonstrated that laryngoscopy and intubation were associated with an increase in BIS during target-controlled infusion of propofol. In agreement with these reports, we found that tracheal intubation after anesthetic induction with thiamylal and fentanyl also significantly increased BIS.

It is well known that patients with hypertension show greater pressor responses to tracheal intubation than do normotensive patients. ${ }^{7,8}$ Arteriolar luminal narrowing, blunted baroreflex responses, and increased sympathetic activity in hypertensive patients have been proposed to be factors responsible for the exaggerated hemodynamic changes. ${ }^{10,11}$ These responses should increase the risk of perioperative complications, including myocardial ischemia, cardiac failure, and intracranial hemorrhage.

Addition of induction agents ${ }^{12}$ or inhalational anesthetics ${ }^{13}$ are frequently used before tracheal intubation to blunt circulatory responses, but may deepen both the hypnotic and antinociceptive components of anesthesia. We found that normotensive and hypertensive patients showed similar increases in BIS after tracheal intubation, indicating that there was no difference in the intubation-induced arousal responses in these two groups of patients. Therefore, although hypertensive and normotensive patients require the same amount of anesthetics to control the level of hypnosis during noxious stimulation as that given to normotensive patients, supplementary anesthetic agents are needed to suppress the sympathetic responses in the former.

We conclude that patients with and without hypertension show the same arousal response to tracheal intubation despite the well known enhanced hyperdynamic response in hypertensive patients.

\section{References}

I Sebel PS, Lang E, Rampil IJ, et al. A multicenter study of bispectral electroencephalogram analysis for monitoring anesthetic effect. Anesth Analg 1997; 84: 891-9.

2 Iselin-Chaves IA, Flaishon R, Sebel PS, et al. The effect of the interaction of propofol and alfentanil on recall, loss of consciousness, and the bispectral index. Anesth Analg 1998; 87: 949-55.

3 Glass PS, Bloom M, Kearse L, Rosow C, Sebel P, Manberg $P$. Bispectral analysis measures sedation and memory effects of propofol, midazolam, isoflurane, and alfen- tanil in healthy volunteers. Anesthesiology 1997; 86: 836-47.

4 Mi W-D, Sakai T, Takahashi S, Matsuki A. Haemodynamic and electroencephalograph responses to intubation during induction with propofol or propofol/fentanyl. Can J Anaesth 1998; 45: 19-22.

5 Guignard B, Menigaux C, Dupont X, Fletcher D, Chauvin $M$. The effect of remifentanil on the bispectral index change and hemodynamic responses after orotracheal intubation. Anesth Analg 2000; 90: 161-7.

6 Coste C, Guignard B, Menigaux C, Chauvin M. Nitrous oxide prevents movement during orotracheal intubation without affecting BIS value. Anesth Analg 2000; 91: 130-5.

7 Prys-Roberts C, Greene LT, Meloche R, Fö̈x P. Studies of anaesthesia in relation to hypertension. II: haemodynamic consequences of induction and endotracheal intubation. Br J Anaesth 1971; 43: 531-45.

8 Omote K, Kirita A, Namiki A, Iwasaki $H$. Effects of nicardipine on the circulatory responses to tracheal intubation in normotensive and hypertensive patients. Anaesthesia 1992; 47: 24-7.

9 Kanaya N, Nakayama M, Fujita S, Namiki A. Haemodynamic and EEG changes during rapidsequence induction of anaesthesia. Can J Anaesth 1994; 41: 699-702.

10 Low JM, Harvey JT, Prys-Roberts C, Dagnino J. Studies of anaesthesia in relation to hypertension. VII: adrenergic responses to laryngoscopy. Br J Anaesth 1986; 58 : 471-7.

11 Ishikawa T, Nishino T, Hiraga $K$. Immediate responses of arterial blood pressure and heart rate to sudden inhalation of high concentrations of isoflurane in normotensive and hypertensive patients. Anesth Analg 1993; 77: 1022-5.

12 Unni VKN, Johnston RA, Young HSA, McBride RJ. Prevention of intracranial hypertension during laryngoscopy and endotracheal intubation. Use of a second dose of thiopentone. Br J Anaesth 1984; 56: 1219-23.

13 Kautto $U-M$, Saarnivaara L. Attenuation of the cardiovascular intubation response with $\mathrm{N}_{2} \mathrm{O}$, halothane or enflurane. Acta Anaesthesiol Scand 1983; 27 : 289-93. 